\title{
TRÊS CATEGORIAS QUE MARCARAM A PEDAGOGIA DO OPRIMIDO
}

\author{
THREE CATEGORIES THAT MARKED THE PEDAGOGY OF THE OPRIMIDO
}

TRES CATEGORÍAS QUE MARCARON LA PEDAGOGÍA DEL OPRIMIDO

\section{Angela Biz Antunes 1 \\ Moacir Gadotti ${ }^{2}$ \\ Paulo Roberto Padilha ${ }^{3}$}

RESUMO: Este ensaio, escrito a seis mãos, trata de uma difícil escolha: dentre os inúmeros conceitos e categorias desenvolvidos por Paulo Freire em sua obra máxima, Pedagogia do oprimido, os autores tiveram de selecionar apenas três e sobre eles desenvolver uma reflexão que permitisse conhecer, um pouco mais em profundidade, os fundamentos do legado de nosso educador maior. Foram escolhidos os conceitos de "diálogo", "liberdade" e "oprimido" que, no entendimento dos autores são princípios fundantes na obra de Freire, na medida em que eles seriam retomados e reinventados, pelo próprio Freire, nos novos contextos em que produziu suas demais obras.

PALAVRAS-ChaVE: Diálogo. Oprimido. Liberdade. Pedagogia.

ABSTRACT: This essay, written by six hands, deals with a difficult choice: among the many concepts and categories developed by Paulo Freire in his maximal work, Pedagogy of the Oppressed, the authors had to select only three and on them to develop a reflection that allowed to know, a little more in depth, the foundations of the legacy of our greatest educator. The concepts of "dialogue", "freedom" and "oppressed" were chosen in the authors' understanding as founding principles in Freire's legacy, since they would be retaken and reinvented by Freire himself in the new contexts in which he produced his other works.

KEYWORDS: Dialogue. Oppressed. Freedom. Pedagogy.

RESUMEN: Este ensayo, escrito a seis manos, trata de una difícil elección: entre los innumerables conceptos y categorías desarrollados por Paulo Freire en su obra máxima, Pedagogía del oprimido, los autores tuvieron que seleccionar sólo tres y sobre ellos desarrollar una reflexión que permitiese conocer, un poco más en profundidad, los fundamentos del legado de nuestro educador mayor. Se eligieron los conceptos de "diálogo", "libertad" y "oprimido" que, en el entendimiento de los autores, son principios fundantes en la obra de Freire, en la medida en que ellos serían retomados y reinventados, por el propio Freire, en los nuevos contextos en que produjo sus demás obras.

PALABRAS ClAVE: Diálogo. Oprimido. Libertad. Pedagogía.

\section{INTRODUÇÃO}

Não é fácil escolher entre os principais conceitos e categorias que sustentam a obra Pedagogia do oprimido de Paulo Freire. É claro, salta aos olhos a categoria central do livro: "oprimido". Desta, ocorrem-nos outras duas intimamente relacionadas: "liberdade" e “diálogo". A primeira remete ao processo de constituição do sujeito na história. A segunda, à

${ }^{1}$ Submetido em: 07/01/2019 - Aceito em: 13/01/2019 - Publicado em: 16/01/2019

\begin{tabular}{l|l|l|l|l|l|l} 
(C) Rev. Educ. Perspec. & Viçosa, $M G$ & v.9 & n.2 & p.514-526 & set./dez. 2018 & eISSN 2178-8359 \\
\hline
\end{tabular}


"vocação ontológica" do sujeito se constituindo com o outro. Estão aí três conceitos e categorias - oprimido, liberdade e diálogo - sobre os quais teceremos reflexões, relacionando-os à educação contemporânea e, assim, atendendo à solicitação da Universidade Federal de Viçosa, associamo-nos às celebrações dos 50 anos da Pedagogia do oprimido.

\section{OPRIMIDO}

A educação, espaço da paideia e da utopia, é um campo fértil de paradigmas. A história das ideias pedagógicas revela uma grande riqueza de orientações, teorias e práticas educacionais. Seria errôneo dizer que existe apenas uma educação. Existem muitas educações que seguem orientações, teorias e paradigmas distintos.

Alguns poderiam dizer que a existência de muitas educações possíveis enfraqueceria o campo educacional, tornando-o mais frágil, porque mais diverso. Essa, porém, não é uma fraqueza da educação, mas a demonstração de sua vitalidade. O que pode enfraquecê-la é a existência de um paradigma imposto ou exclusivo. Essa é a tentação autoritária dos paradigmas: estabelecer parâmetros como modelos universais. Encontramos muitos "ismos" em educação que podem ser delimitados por tendências, vertentes, perspectivas diferentes. Assim, podemos falar de uma pluralidade paradigmática na educação.

A ideia de uma teoria universal da educação está em crise. Mais do que fechar-se num único modelo de ciência, precisamos promover o diálogo entre distintos saberes e criar zonas de contato entre teorias e práticas distintas. É claro que sempre existirão ideologias subjacentes a toda prática, explícitas ou não. Isso também não pode ser negado. E como a educação é cultura, o diálogo "intertranscultural" (PADILHA, 2004) é parte integrante dela. Em lugar de aspirar a um universalismo essencialista, deveríamos nos assegurar que haja sempre espaço para a diferença e também para a semelhança, devidamente contextualizadas. Por isso, falamos hoje em redes de conhecimento, em comunidades de aprendizagem, que são aquelas que respeitam a diversidade.

Dito isso, apresentamos algumas considerações sobre a teoria da educação emancipatória de base freiriana e que poderíamos chamar de "paradigma do oprimido" (GADOTTI, 2005). Não se trata de um paradigma fechado; trata-se de uma teoria e de um método abertos, inclusivos e em evolução. Não é um paradigma inventado por alguém, mas enraizado no movimento histórico-social da educação popular, ela também uma concepção geral da educação e um paradigma.

Paulo Freire é personagem central desse paradigma, guiado por um sonho, por uma utopia, pela confiança num "outro mundo possível", porque "o mundo não é, o mundo está sendo"

\begin{tabular}{l|c|c|c|c|c|c} 
() Rev. Educ. Perspec. & Viçosa, $M G$ & v.9 & n.2 & p.514-526 & set./dez. 2018 & eISSN 2178-8359 \\
\hline
\end{tabular}


(FREIRE, 1997, p. 86). Ele defendia uma compreensão da educação cheia de perguntas, mas também cheia de esperança. Esse paradigma orientou sua práxis político-pedagógica e continua sendo o referencial de muitos educadores e de muitas educadoras, espalhados pelo mundo.

Paulo Freire costumava falar numa racionalidade encharcada de emoção, contrapondo o seu paradigma dialético ao paradigma estrutural, contrapondo uma razão contextualizada e referenciada na historicidade à razão cartesiana, positivista e instrumental. Na razão dialética, a categoria de totalidade é recuperada: o sentido das coisas não é apreendido apenas pela análise racional, mas pela totalidade do aparato epistemológico humano: afetividade/sensibilidade-racionalidade/ciência. E é neste sentido que a teoria freiriana explicita, com mais profundidade e consequência, a dimensão da transdisciplinaridade.

O que mais o preocupava, nos últimos anos de sua vida, era o avanço perverso da globalização capitalista neoliberal. Por que Paulo Freire atacava tanto o pensamento e a prática neoliberal? Porque o neoliberalismo é visceralmente contrário ao núcleo central do seu pensamento que é a utopia. Enquanto o pensamento freiriano é utópico, o pensamento neoliberal abomina o sonho. Para Paulo Freire, o futuro é possibilidade. Para o neoliberalismo, o futuro é pura fatalidade. O neoliberalismo apresenta-se como única resposta à realidade atual, desqualificando qualquer outra proposta. Desqualifica principalmente o Estado, os sindicatos, os partidos políticos e a própria política. Paulo Freire denunciava a política fazendo política. Ele atacava a ética do mercado, sustentada pelo neoliberalismo, porque ela tem por base a lógica do controle, e afirmava, contrapondo-se àquela, uma "ética universal do ser humano" (FREIRE, 1997, p. 16). O neoliberalismo tenta nos convencer de que a globalização capitalista é uma realidade definitiva e não uma categoria histórica. Precisamos de uma outra globalização ou de uma alterglobalização, como sustenta o Fórum Social Mundial (GADOTTI, 2007).

A concepção de mundo e a teoria sócio-político-educativa de Paulo Freire nos ajudam não apenas a entender melhor como funciona o modelo neoliberal, mas nos ajudam a construir a resposta necessária ao neoliberalismo. Ele defende uma nova modernidade fundada na racionalidade dialógica, essencialmente comunicativa. Contra o iluminismo pedagógico e cultural, que acentua apenas a aquisição de conteúdos curriculares, ele realça a importância da dimensão cultural nos processos de transformação social. A educação é muito mais do que a instrução. Para ser transformadora - transformar as condições de opressão - ela deve enraizar-se na cultura dos povos. A modernidade capitalista se caracteriza pela espetacularização de tudo, pelo simulacro e pelo consumo imediato. Ora, a educação é um processo a longo prazo e precisa combater o imediatismo, o consumismo, se quiser contribuir para a construção de uma pós-modernidade progressista, uma nova modernidade. A

\begin{tabular}{|c|c|c|c|c|c|c|} 
(C) Rev. Educ. Perspec. & Viçosa, $M G$ & v.9 & n.2 & p.514-526 & set./dez. 2018 & eISSN 2178-8359 \\
\hline
\end{tabular}


educação, para ser libertadora, precisa construir entre educadores e educandos uma verdadeira consciência histórica. E isso demanda tempo.

Paulo Freire colocou o oprimido no palco da história - como ator, autor e sujeito de sua história - pelo seu engajamento político e pela sua teoria como contra-narrativa ao discurso dos poderosos e privilegiados. Ele valorizava, além do saber científico elaborado, também o saber primeiro, o saber da vida cotidiana. Ele sustentava que quem aprende não registra em separado as significações instrutivas das significações educativas e cotidianas. Ao incorporar conhecimento, o/a estudante incorpora outras significações e linguagens: como conhecer, como se produz e como a sociedade utiliza o conhecimento; enfim, o saber da vida cotidiana de seu grupo social.

Outra noção que ele desenvolveu e que a distingue de toda a conotação neoliberal, é a noção de qualidade como um conceito ético-político. Quando estava à frente da Secretaria Municipal de Educação de São Paulo (1989-1991) ele nos falava de uma nova qualidade, uma qualidade social e política da educação. Qualidade é empenho ético, alegria de aprender. Para o pensamento neoliberal, a qualidade se confunde com a competitividade. Os neoliberais negam a necessidade da solidariedade. Contudo, as pessoas não são competentes porque são competitivas, mas porque têm um projeto de vida e porque sabem enfrentar seus problemas cotidianos junto com os outros e não individualmente. Por isso mesmo, nós, que procuramos continuar e reinventar o legado de Paulo Freire, como ele mesmo nos sugeriu, falamos hoje em qualidade sociocultural e socioambiental da educação, reconhecendo e reafirmando a necessidade de valorizarmos, no processo de ensino e de aprendizagem, da qualidade substantiva que enfatiza a superação da desigualdade social e da exclusão cultural (PADILHA, 2004; 2012).

O reconhecimento de Paulo Freire, para além do campo da pedagogia, demonstra que o seu pensamento é também transdisciplinar e transversal. Desde seus primeiros escritos, considerou a escola muito mais do que as quatro paredes da sala de aula. Criou o "Círculo de Cultura”, como expressão dessa nova pedagogia que não se reduzia à noção simplista de aula. $\mathrm{Na}$ sociedade do conhecimento de hoje, isso é ainda mais atual, já que o espaço escolar é muito maior do que a escola.

Os novos espaços da formação (mídia, rádio, TV, vídeo, igrejas, sindicatos, teatros, empresas, ONGs, espaço familiar, espaços comunitários, virtuais etc.) alargaram a noção de escola e de sala de aula. A educação tornou-se comunitária, virtual, multicultural e ecológica. Com isso, a escola estendeu-se para a cidade e o planeta. Hoje se pensa em rede, pesquisa-se em rede, trabalha-se em rede, sem hierarquias. A noção de hierarquia (saber-ignorância) é muito cara à escola capitalista. Ao contrário, Paulo Freire insistia na conectividade, na gestão coletiva do conhecimento social a ser socializado de forma ascendente. Não se trata mais de

\begin{tabular}{|c|c|c|c|c|c|c|}
\hline (C) Rev. Educ. Perspec. & Viçosa, $M G$ & v.9 & n. 2 & p.514-526 & set./dez. 2018 & eISSN 2178-8359 \\
\hline
\end{tabular}


ver apenas a cidade ou o município como educadores, mas de enxergar o planeta Terra como uma escola permanente. Decorre daí a ideia da Educação para a Cidadania Planetária.

O livro Pedagogia do oprimido foi escrito no Chile em 1968. A pergunta que podemos fazer hoje é a seguinte: a pedagogia sob a perspectiva do oprimido é ainda válida e necessária? Se negássemos sua validade, já não haveria mais porque continuar lendo Paulo Freire. Ou melhor, Paulo Freire seria um autor já superado, porque sua luta pelo oprimido estaria superada. Ele passaria para a história como um grande educador, mas que não teria mais nada a dizer ao nosso tempo.

Pelo contrário, a sua pedagogia continua válida não só porque ainda há opressão no mundo, mas porque ela reponde às necessidades fundamentais da educação de hoje. A escola e os sistemas educacionais encontram-se hoje frente a novos e grandes desafios. As cidades estão se tornando educadoras e aprendentes, multiplicando seus espaços de formação. À escola está posto o desafio de, na era da informação, assumir-se como um "Círculo de Cultura", como dizia Paulo Freire, muito mais gestora do conhecimento sociocultural e socioambiental, do que lecionadora.

O livro Pedagogia do oprimido acabou dando origem a uma concepção de educação, sustentada hoje pelos educadores populares, pelos movimentos sociais e que fundamenta experiências exitosas na educação formal, da educação infantil à pós-graduação. Segundo Miguel Arroyo (2012, p. 554), Pedagogia do oprimido "é uma concepção e prática pedagógica construídas e reconstruídas nas experiências sociais e históricas de opressão e nas resistências dos oprimidos, dos movimentos sociais pela libertação de tantas formas persistentes de opressão". É nascida nas experiências sociais e inseparável dos sujeitos dessas experiências como produtores de conhecimentos e reconstruída por esses mesmos sujeitos.

A categoria "oprimido" abre um campo ainda maior em direção à uma "civilização do oprimido" (ROMÃO, 2004), entendida como o contrário da barbárie e da selvageria. Como sustenta José Eustáquio Romão, falando do livro Pedagogia do oprimido:

para mim, sua marca mais impressionante, seja pela clarividência epistemológica, seja pela coragem política de seu autor, é o fato de ser, não uma "pedagogia para o oprimido", mas uma "pedagogia do oprimido", isto é, uma formulação a partir do ponto de vista dos esfarrapados da Terra, a quem ele dedica o livro. A implicação desta opção é radical, constituindo, no limite, uma verdadeira revolução paradigmática, na medida em que atribui aos dominados uma superioridade científica e epistemológica. Esta superioridade é explicitada na passagem em que Paulo Freire afirma: "Por isto é que somente os oprimidos, libertando-se, podem libertar os opressores. Estes, enquanto classe que oprime, nem libertam, nem se libertam" (Pedagogia do oprimido, $17^{\mathrm{a}}$ ed., p. 43). Estendendo-se este princípio aos demais campos da atividade humana, pode-se concluir que somente os oprimidos são capazes de desenvolver a humanização e, portanto, o processo civilizatório (ROMÃO, 2008, p. 11-12). 


\section{LIBERDADE}

Numa das manifestações que ocorreram no Brasil, em 2015, havia uma faixa que pedia que a obra de Paulo Freire fosse retirada das escolas. Tratava-se de uma posição políticoideológica. A política costuma dividir uns e unir outros. $\mathrm{O}$ que não é ruim, pois favorece o debate, a crítica e, também, o diálogo. Aprendemos na diferença.

Paulo Freire, como pessoa, pode ser considerado uma unanimidade, mas, como pensador não poderia agradar a todo mundo. Muitos não gostaram, por exemplo, que ele tenha sido proclamado, em 2012, "patrono da educação brasileira". Nenhuma teoria pedagógica agrada a todos e todas e isso é muito bom. Tinha posições firmes e bem fundamentadas. Valorizava as críticas, sustentando que podemos sempre aprender com elas. Ele escreveu seu livro Pedagogia da esperança (1992), fazendo uma leitura crítica de sua principal obra, a Pedagogia do oprimido (1968), que poderia ser chamada de "Pedagogia da libertação".

Ele era uma pessoa alegre e bem-humorada. Mas, às vezes, é difícil manter o bom humor diante de algumas críticas, sobretudo quando são pessoais. Mesmo assim, Paulo jamais respondeu a qualquer ataque pessoal. Sobre a faixa que mencionamos antes, certamente, não responderia, mas, pensaria que, por trás dela, estaria escondida uma postura de classe, de quem, talvez, nunca tenha lido um livro dele.

Ele não odiava ninguém. Era uma pessoa muito simples, um educador preocupado com a construção de uma sociedade mais justa, mais democrática, querendo contribuir "na criação de um mundo em que seja menos difícil amar" (FREIRE, 1974, p. 218), como diz ele na frase final de sua Pedagogia do oprimido.

Dizia que toda educação supõe uma visão de mundo, um projeto de sociedade. Por isso, toda educação é política. Assim podemos ter uma pedagogia que oprime e uma pedagogia que liberta. Aqui entra o tema da libertação na educação.

Como muitos dos seus intérpretes afirmam, a tese central da sua obra é a da liberdade/libertação. A liberdade é a categoria central de sua concepção educativa desde suas primeiras obras. A libertação é o fim da educação. A finalidade da educação será libertar-se da realidade opressiva e da injustiça. A educação visa à libertação, à transformação radical da realidade, para melhorá-la, para torná-la mais humana, para permitir que homens, mulheres e pessoas não binárias sejam reconhecidos como sujeitos da sua história e não como objetos.

A libertação, como fim da educação, situa-se no horizonte de uma visão utópica da sociedade. A educação, a formação, devem permitir uma leitura crítica do mundo. O mundo que nos rodeia é um mundo inacabado e isso implica a denúncia da realidade opressiva, da

\begin{tabular}{l|l|l|l|l|l|l} 
(C) Rev. Educ. Perspec. & Viçosa, $M G$ & v.9 & n.2 & p.514-526 & set./dez. 2018 & eISSN 2178-8359 \\
\hline
\end{tabular}


realidade injusta (inacabada) e, consequentemente, de crítica transformadora, portanto, de anúncio de outra realidade. $\mathrm{O}$ anúncio é necessário como um momento de uma nova realidade a ser criada. Essa nova realidade do amanhã é a utopia do educador de hoje. Para Paulo Freire, a utopia é o realismo do educador. Não pode ser realista o educador que não é utópico. Ter o direito de ser utópico e manifestar a utopia como inédito viável, diante das situações-limites do nosso tempo, é também uma forma de lutar e de avançar na conquista da liberdade que, enquanto é sonhada, também vai se realizando, processualmente. Diríamos que é um "estar-sendo" livre e conquistando a liberdade aos poucos.

Educação não é só ciência: é arte e práxis, ação-reflexão, conscientização, projeto e transformação. Como projeto, a educação precisa reinstalar a esperança. Nada mais atual do que esse pensamento, numa época em que muitos educadores vivem alimentados mais pelo desencanto do que de esperança.

A relação entre educação, libertação e utopia está na base do pensamento freiriano. Ela pode ser resumida em quatro princípios:

$1^{\circ}$ - Para construir o futuro é preciso primeiro sonhá-lo, imaginá-lo. No seu último livro, Pedagogia da autonomia, ele critica o neoliberalismo exatamente por negar o sonho, por ser fatalista, por negar a possibilidade de mudança. Para ele o neoliberalismo se apresenta, arrogantemente, como a plenitude dos tempos, não reconhece que a história continua se fazendo. O neoliberalismo afirma o "fim da história" porque não lhe interessa que a história mude. Interessa sim que ela continue como está.

$2^{\circ}$ - A pedagogia é um guia na construção do sonho. Não basta sonhar. É preciso saber como construir o sonho. Paulo Freire apresentou os seus "saberes necessários" para realizar o sonho. Ofereceu em Pedagogia da autonomia, a mediação pedagógica necessária para conquistá-lo. Todos os livros de Paulo Freire são livros de pedagogia, isto é, são livros destinados à educação para construir o sonho, uma educação libertadora.

$3^{\circ}$ - A pedagogia vê primeiro o futuro, um futuro melhor para todos, a utopia. Depois é que ela se volta para o presente e para o passado.

$4^{\circ}$ - A pedagogia freiriana é dialógico-dialética. Não mecânica. A dialética continua válida desde que não exclua a subjetividade. Caso contrário ela se transforma numa mecânica sem sentido que lembra a divina providência cristã. A dialética mecanicista é idealista e idealizadora da realidade (GADOTTI, 2000, p. 04 , grifo dos autores).

A liberdade foi uma categoria muito cara a Paulo Freire. Certamente ele defenderia a liberdade de quem, em praça pública, pedisse que sua pedagogia fosse retirada das escolas, pois ele defendia a liberdade de expressão. Mas ele distinguia as diversas concepções de liberdade. Seu primeiro livro, publicado em 1967, tem por título: Educação como prática da liberdade. A educação libertadora seria uma educação eminentemente problematizadora da realidade opressiva. 
Para Paulo Freire, a educação libertadora era uma educação crítica, o contrário da educação dogmática, sectária. Ele distinguia a educação sectária da educação radical, isto é, uma educação que investiga os fundamentos, as raízes das coisas e não fica na superficialidade.

As pedagogias clássicas também tratam deste tema, sobretudo do ponto de vista psicológico, opondo, na relação pedagógica, a liberdade do educando e a autoridade do educador. A pedagogia tradicional centrava a educação no educador e a pedagogia nova no educando. Paulo Freire não centrou a educação no educador e nem no educando, mas na relação entre os dois. Daí a importância que ele dava aos vínculos, à relação, à cultura e à mediação pedagógica.

\section{DIÁLOGO}

Paulo Freire opõe a educação problematizadora do oprimido, à educação bancária do opressor: a primeira leva à humanização e a segunda à "manutenção objetiva da opressão"; a primeira caracteriza-se pela "colaboração, pela união, pela organização e pela síntese cultural"; a segunda caracteriza-se pela "conquista, pela divisão do povo, pela manipulação e pela invasão cultural” (GADOTTI, 2016, s.p.)

Para ele, ninguém liberta ninguém. Todos nos libertamos juntos, em comunhão. Karl Marx sustentava que os trabalhadores só podem libertar-se por eles mesmos. Freire vai mais além: todos os seres humanos precisam libertar-se por eles mesmos. Uma das categorias fundamentais da pedagogia do oprimido é a autodeterminação, ainda pouco explorada e muito menos promovida nas nossas escolas.

Autonomia não significa isolamento, autossuficiência. A emancipação não é um ato isolado. Precisamos do outro para nos completar. Daí a necessidade do diálogo. Não se pode entender o conceito de autonomia em Freire desvinculado do conceito de diálogo e da amorosidade, condição básica do próprio diálogo, conforme veremos a seguir.

Eis como ele vê o processo de libertação, pela emancipação, pela conquista da autonomia do colonizado, tornando-se sujeito de sua história. É aqui que entra a categoria diálogo, relacionada com outra categoria: autonomia, conceitos esses desenvolvidos em seu livro Pedagogia do oprimido.

O professor Ernani Maria Fiori no prefácio do livro Pedagogia do oprimido resume a noção de autonomia do sujeito e de sua construção, em Paulo Freire, a partir de cinco afirmações: $1^{\text {a }}$. "Com a palavra o homem se faz homem" (FIORI, 1974, p. 5). Fiori destaca que o limiar entre os seres humanos e outros seres é a palavra; para assumir a condição humana o ser

\begin{tabular}{l|c|c|c|c|c|c} 
(C) Rev. Educ. Perspec. & Viçosa, $M G$ & v.9 & n.2 & p.514-526 & set./dez. 2018 & eISSN 2178-8359 \\
\hline
\end{tabular}


humano precisava "tomar a palavra"; 2a "Ninguém se conscientiza sozinho" (FIORI, 1974, p. 8): o educando precisa de um educador; a educação não é só aprendizagem: é ensino e aprendizagem; $3^{\mathrm{a}}$. "O mundo se faz pelo trabalho" (FIORI, 1974, p. 10), pelo trabalho cooperativo, juntos; daí a necessidade dos "círculos de cultura" ou "círculos de investigação temática", como Freire os chamou inicialmente; 4". "A palavra verdadeira se faz ação transformadora do mundo" (FIORI, 1974, p. 14), se faz "palavração", diria mais tarde Paulo Freire. Paulo Freire (1974, p. 91) afirma que "não há palavra verdadeira que não seja práxis"; 5. "Aprender a ler é aprender a dizer a sua palavra” (FIORI, 1974, p. 14): ninguém liberta ninguém; todos nos libertamos juntos, em comunhão.

Sua concepção de diálogo foi particularmente desenvolvida no capítulo terceiro de sua Pedagogia do oprimido. Aí ele estabelece cinco condições para o diálogo: 1 ${ }^{\mathrm{a}}$. O amor: "se não amo o mundo, se não amo a vida, se não amo os homens, não me é possível o diálogo" (FREIRE, 1974, p. 80); 2 ${ }^{\mathrm{a}}$. A humildade: "auto-suficiência é incompatível com o diálogo" (FREIRE, 1974, p. 81); 3ª A fé nos homens: "fé na sua vocação de ser mais" (FREIRE, 1974, p. 81); "sem a fé nos homens o diálogo é uma farsa" (FREIRE, 1974, p. 81); 4". A esperança: "a esperança está na própria essência da imperfeição dos homens, levando-os a uma eterna busca" (FREIRE, 1974, p. 82) e $5^{\text {a }}$. O pensar crítico. Para Paulo Freire o pensar ingênuo é "acomodação" (FREIRE, 1974, p. 83): "somente o diálogo, que implica um pensar crítico, é capaz, também de gerá-lo; sem ele não há comunicação e sem esta não há verdadeira educação" (FREIRE, 1974, p. 83).

Para Paulo Freire, o diálogo se identifica com a própria educação. Para ele o diálogo é uma relação horizontal entre A e B. O diálogo é oposto ao antidiálogo, que implica numa relação vertical de A sobre B. O diálogo é crítico e o antidiálogo é acrítico, autossuficiente, desesperançoso, arrogante. Na relação não dialógica não há comunicação. Por isso, essa relação impede as pessoas de construírem sua autonomia.

Se é pela palavra que o ser humano revela sua humanidade, é no diálogo que ele se encontra com o outro, completando sua humanidade. Só por meio de uma comunicação autêntica, na reciprocidade e na igualdade de condições, estabelecidas pelo diálogo, é que o indivíduo torna-se criador e sujeito. Paulo Freire sustenta que a educação não é um processo neutro. Ela pode tanto formar sujeitos sujeitados quanto sujeitos livres. Ela pode ser tanto uma ação cultural para a dominação quanto pode ser uma ação cultural para a libertação. Ela pode ser libertadora ou bancária. Como afirma Ângela Antunes (2008, p. 19):

em Pedagogia do oprimido, Paulo Freire dá nome a algo fundamental no processo educacional. Nomeia o ato de educar como ato político. Traz à existência a politicidade da educação. E, na dedicatória do livro, toma uma posição: 'aos esfarrapados do mundo e aos que com eles sofrem, mas, sobretudo, com eles lutam'. Ensina-nos que educar implica escolhas, compromisso e luta. 
Em Paulo Freire, o diálogo dos oprimidos, orientados por uma consciência crítica da realidade, aponta para a superação do conflito destes com seus opressores. Nele, o diálogo não é só um encontro de dois sujeitos que buscam o significado das coisas - o saber - mas um encontro que se realiza na práxis - ação + reflexão - no engajamento, no compromisso com a transformação social. Dialogar não é trocar ideias. O diálogo que não leva ação transformadora é puro verbalismo.

A pedagogia do oprimido possibilita desvelar a realidade opressora, tornando o homem consciente da situação de exploração em que vive, o primeiro passo para libertar-se da opressão. Trata-se de uma pedagogia que leva à luta pela transformação de opressão na qual o oprimido vive. A pedagogia do oprimido é, ao mesmo tempo, uma pedagogia da esperança e uma pedagogia da luta. Não há esperança na pura espera, sem luta.

Neste livro, Paulo Freire deixa claro que a educação sozinha não poderá decidir sobre os rumos da história; entretanto, mostra como uma educação transformadora pode contribuir para mudar o rumo das coisas. Conscientes e organizados os oprimidos podem libertar-se da opressão. Ele combate a pedagogia fatalista e conservadora, muito presente, sobretudo nos dias atuais, após 50 anos da Pedagogia do oprimido.

Para Paulo Freire, a educação deve ser dialógica e problematizadora, pois educadores, educadoras, educandos e educandas, educam-se no diálogo, mediatizados pelo mundo, tornando-se sujeitos do processo de ensino e de aprendizagem. É o que ele chamou de dodiscência. Ambos aprendem e ensinam juntos, reciprocamente e, mediatizados pela realidade, buscam respostas para os desafios da reflexão e da ação.

Paulo Freire faz a defesa de uma pedagogia dialógica e emancipatória do oprimido, problematizante e participativa, em oposição à pedagogia da classe dominante, que é bancária e domesticadora. Ele propõe a conscientização como forma do povo passar da consciência ingênua, mágica, para a consciência crítica e científica da realidade. $O$ diálogo problematizador, para ele, estabelece-se na relação horizontal, baseada na confiança entre os sujeitos. Este diálogo é, para ele, a essência mesma da educação como prática da liberdade.

\section{ATUALIDADE DA PEDAGOGIA DO OPRIMIDO}

As teorias de Paulo Freire expostas na Pedagogia do oprimido cruzaram as fronteiras das disciplinas, das áreas do conhecimento, das ciências e das artes, para além da América Latina. Suas abordagens transbordaram para outros campos do conhecimento, criando raízes nos mais variados solos, fortalecendo teorias e práticas educacionais, bem como auxiliando reflexões não só de trabalhadores em educação, mas também de médicos, terapeutas,

\begin{tabular}{l|c|c|c|c|c|c|} 
(C) Rev. Educ. Perspec. & Viçosa, $M G$ & v.9 & n.2 & p.514-526 & set./dez. 2018 & eISSN 2178-8359 \\
\hline
\end{tabular}


cientistas sociais, filósofos, antropólogos e outros profissionais. Seu pensamento é considerado um modelo de transdisciplinaridade.

Por que o livro teve tanto reconhecimento, tanta aceitação e por públicos tão diversos?

Há uma razão básica que explica tamanha repercussão: podemos dizer que Paulo Freire faz uma espécie de "metateoria", um discurso que atende a públicos muito diversos e que atravessou tanto as fronteiras geográficas quanto as fronteiras das ciências e das profissões. Isso tem a ver também com a polifonia do seu pensamento. Paulo Freire escreve para educadores e para estudantes, pais e mães, operários, camponeses, para pessoas que não se dedicam estritamente à educação e, na verdade, para todas as pessoas. Pessoas muito diferentes encontraram-se nesse livro, identificaram-se com o seu ponto de vista. O livro ressoou nos mais diversos ambientes, seja na academia, seja na sociedade. Sindicatos, igrejas, movimentos sociais e populares foram responsáveis por uma grande difusão e debate da Pedagogia do oprimido, servindo de guia para a ação transformadora.

Alfabetizadores, intelectuais de esquerda, indígenas, marginalizados, militantes políticos, universitários, pobres e ricos comprometidos com os mais empobrecidos, políticos, trabalhadores sociais e outros, utilizaram-se de suas teses para defender seus próprios pontos de vista e para fortalecer suas lutas.

São ideias simples e revolucionárias que impactaram várias gerações de educadores e de educadoras na América Latina e no Mundo. Muitos educadores, por meio da Pedagogia do oprimido, que despertaram para a luta democrática criando espaços de resistência ao autoritarismo político e pedagógico.

Paulo Freire deixou como legado uma filosofia educacional e um método de investigação e de pesquisa, ancorado numa antropologia e numa teoria do conhecimento, imprescindíveis na formação do educador. Depois de Paulo Freire não se pode mais afirmar que a educação é neutra. Ele demonstrou a importância da educação na formação do povo sujeito, do povo soberano; foi um dos grandes idealizadores do paradigma da educação popular. Miríades de experiências de educação popular e de adultos inspiram-se em suas ideias pedagógicas.

Ele também deu uma grande contribuição à luta pelo direito à educação; não a qualquer educação, mas ao direito a uma educação emancipadora. Sua pedagogia destacou a necessidade de teorizar a prática, a necessidade da pesquisa participante, o reconhecimento da legitimidade do saber popular, ao mesmo tempo em que sempre valorizou a cultura, as artes, a comunicação e o uso crítico das tecnologias associadas à educação. 
A atualidade da Pedagogia do oprimido é demonstrada não só pelo número de suas edições, mas pelas marcas que ela deixou na educação do século $\mathrm{XX}$, também neste início do novo milênio: muitos centros de estudos, cátedras, institutos, associações e entidades públicas e privadas fundamentam-se hoje em Freire e desenvolvem estudos sobre ele. Sua pedagogia está comprometida com a cidadania, com a autonomia do aluno, uma concepção pedagógica amplamente aceita hoje. Paulo Freire recusou o pensamento fatalista neoliberal, o que lhe dá uma inquestionável posição de vanguarda frente às concepções pedagógicas conservadoras que não se preocupam com a ética e a radicalização da democracia.

O livro Pedagogia do oprimido continua muito atual, não só porque ainda existem oprimidos, mas porque é uma obra de grande valor para todos os que buscam, por meio da educação, criar "um mundo em que seja menos difícil amar" (FREIRE, 1974, p. 218), como afirma ao terminá-lo. É um livro fundamental para aqueles que não se conformam com o pensamento único neoliberal, que renuncia ao sonho e a utopia; para aqueles que acreditam que "um outro mundo é possível" e que outras educações também são possíveis, como sustentam, respectivamente, o Fórum Social Mundial e o Fórum Mundial de Educação, dos quais participamos desde seu início; e para quem a palavra "oprimido" não perdeu vigência, não perdeu sentido e, tampouco, atualidade.

\section{Por que continuar lendo Pedagogia do oprimido?}

Alguns certamente gostariam de deixar esse livro nas prateleiras, no passado, para trás, na história das ideias pedagógicas; outros gostariam de esquecê-lo, por causa das opções políticas assumidas por Freire. Certamente, não é um livro que agrada a todos. Em certos lugares, até hoje, ele é um livro interditado. Mas, para os que desejam conhecer e viver uma pedagogia de inspiração humanista, esta é uma obra imprescindível. A pedagogia do diálogo que este livro defende, fundamenta-se numa filosofia pluralista. A força desta obra não está só na sua teoria do conhecimento, mas em mostrar uma direção, mostrar que é possível, urgente e necessário mudar a ordem das coisas. Paulo Freire não só convenceu tantas pessoas, em tantas partes do mundo, por suas teorias e práticas, mas também porque despertou nelas a capacidade de sonhar com uma realidade mais humana, menos feia e mais justa. Como legado nos deixou a utopia.

\section{REFERÊNCIAS}

ANTUNES, Ângela. Pedagogia do oprimido: escolha, compromisso e luta. In: GADOTTI, Moacir (Org.). 40 olhares sobre os 40 anos da Pedagogia do oprimido. São Paulo: Instituto Paulo Freire, p. 19-20, 2008.

ARROYO, Miguel Gonzalez. Pedagogia do oprimido. In: CALDART, Roseli Salete; PEREIRA, Isabel Brasil; ALENTEJANO, Paulo; FRIGOTTO, Gaudêncio (Org.). Dicionário da educação no campo. São Paulo: Expressão Popular, p. 553-561, 2012.

\begin{tabular}{l|c|c|c|c|c|c} 
(C) Rev. Educ. Perspec. & Viçosa, $M G$ & v.9 & n.2 & p.514-526 & set./dez. 2018 & eISSN 2178-8359 \\
\hline
\end{tabular}


FIORI, Ernani Maria. Prefácio: Aprender a dizer sua palavra. In: FREIRE, Paulo. Pedagogia do oprimido. São Paulo: Paz e Terra, 1974.

FREIRE, Paulo. Pedagogia do oprimido. São Paulo: Paz e Terra, 1974.

FREIRE, Paulo. Pedagogia da autonomia: saberes necessários à prática educativa. São Paulo: Cortez, 1997.

GADOTTI, Moacir. Saber aprender: um olhar sobre Paulo Freire e as perspectivas atuais da educação. Centro de Referência Paulo Freire, p. 01-08, 2000. Disponível em:

<http://www.acervo.paulofreire.org:8080/jspui/handle/7891/1125>. Acesso em: 13 jun. 2018.

GADOTTI, Moacir. O paradigma do oprimido. Revista Pátio. Porto Alegre, v. 4, n. 35, p. 12-15, ago./out. 2005.

GADOTTI, Moacir. Educar para um outro mundo possível: o Fórum Social Mundial como espaço de aprendizagem de uma nova cultura política e como processo transformador da sociedade civil planetária. São Paulo, Publisher Brasil, 2007.

GADOTTI, Moacir (Org.). 40 olhares sobre os 40 anos da pedagogia do oprimido. São Paulo: Instituto Paulo Freire, 2008.

GADOTTI, Moacir. Escola sem partido, uma escola a favor da cultura da indiferença. Carta Educação, 05 set. 2016. Disponível em: http://www.cartaeducacao.com.br/artigo/escola-sempartido-uma-escola-a-favor-da-cultura-da-indiferenca/. Acesso em: 13 jun. 2018.

PADILHA, Paulo Roberto. Currículo intertranscultural: novos itinerários para a educação. São Paulo: IPF/Cortez, 2004.

PADILHA, Paulo Roberto. Educar em todos os cantos: por uma educação intertranscultural. São Paulo: Editora e Livraria Instituto Paulo Freire, 2012.

ROMÃO, José Eustáquio. A civilização do oprimido. Revista Lusófona de Ciências Sociais. Lisboa: Universidade Lusófona, n. 1, p. 31- 47, 2004.

ROMÃO, José Eustáquio. Opção radical pelo oprimido. In: GADOTTI, Moacir (Org.). 40 olhares sobre os 40 anos da Pedagogia do oprimido. São Paulo: Instituto Paulo Freire, p. 11-12, 2008.

\section{Sobre os Autores}

${ }^{1}$ Angela Biz Antunes - Doutora em Educação pela Universidade de São Paulo. E-mail: angela.bizantunes@paulofreire.org - ORCID: http://orcid.org/0000-0003-4342-1043

${ }^{2}$ Moacir Gadotti - Doutor em Educação pela Universidade de Genebra. E-mail: moacir.gadotti@paulofreire.org - ORCID: http://orcid.org/0000-0001-7565-2618

${ }^{3}$ Paulo Roberto Padilha - Doutor em Educação pela Universidade de São Paulo. E-mail: paulo.padilha@paulofreire.org - ORCID: http://orcid.org/0000-0001-8805-7121

\begin{tabular}{l|c|c|c|c|c|c} 
(C) Rev. Educ. Perspec. & Viçosa, $M G$ & v.9 & n.2 & p.514-526 & set./dez. 2018 & eISSN 2178-8359 \\
\hline
\end{tabular}

